\author{
ALEKSANDR TSOI \\ Uniwersytet Łódzki, Wydział Filologiczny, Instytut Rusycystyki, \\ Zakład Językoznawstwa
}

\title{
Результаты анализа словарей дискурсивных слов
}

Дискурсом называется связный текст, произносимый в определенной ситуации и с определенными задачами. Наряду с термином дискурс в лингвистике используется термин дискурсивное слово, который впервые в научный оборот ввел французский лингвист Антуан Кальоли [Плунгян, Рахилина 1994: 107-111].

Дискурсивными словами называют особую группу слов, которую в традиционной лингвистике относят к «частицам», «модальным словам», «союзам», «наречиям». В русском языке это, например, частицы «же», «ведь», «ну», «вот» и другие, союзы «и», «или», «только», «так как», наречие «прямо» и т. д. Наряду с понятием дискурсивного слова в работах зарубежных лингвистов используется понятие дискурсивной частищьы. С точки зрения культуры русской устной речи эти слова не должны употребляться, поскольку засоряют речь, делают ее громоздкой, неуправляемой. Многие лингвисты считают, что речь человека, которая заполнена такими словами, свидетельствует о его низкой речевой культуре, отсутствии словарного запаса. С другой стороны, следует учесть, что в процессе неподготовленной речи возникают такие ситуации, когда человек затрудняется в выборе лексических единиц, значения которых были бы понятны собеседнику. В таких ситуациях адресант речи, подыскивая необходимые слова, заполняет паузы такими словами-паразитами.

Некоторые исследователи, например В. Плунгян, полагают, что естественный русский дискурс без этих слов будет выглядеть суховато, дистиллировано. Он считает, что эти слова-паразиты совершенно необходимы и автору, и адресату речи: они помогают строить дискурс или, как ещё говорят лингвисты, обеспечивают связность текста. «Почти каждое предложение 
в процессе свободного речевого общения будет начинаться либо с «э-э-э», либо с «а», либо с «ну», либо с «вот». Казалось бы, эти слова ничего не значат, но на самом деле у них огромный спектр значений, и эти значения очень важны» [Плунгян 2013].

Лексикографическое описание дискурсивных слов на основе учета взаимодействия коммуникативных единиц с контекстом осуществлено в Путеводителе по дискурсивныл словам [Баранов, Плунгян, Рахилина 1993] и в словаре Дискурсивные слова русского языка: Опыт контекстно-семантического описания [Дискурсивные слова... 1998]. Эти два произведения лексикографического жанра свидетельствуют о тенденции усиления внимания к проблеме отражения инварианта лексических значений служебных слов и наречий, которые выступают в речи в функции дискурсивных слов. Описание дискурсивных слов русского языка представляет собой лексикографическую проблему, связанную с уникальным поведением каждого отдельного служебного слова. Для их кодификации в словарной статье необходимы выявление, фиксация и целенаправленный отбор большого числа параметров. К дискурсивным словам отнесены частицы и модальные слова, союзы и наречия, важным свойством которых является их непосредственная связь с функционированием устной речи. По классификации В. В. Виноградова большинство дискурсивных слов относится к модальным словам. Близость частиц и модальных слов - функционально-семантическая, она определяет точку зрения говорящего субъекта на отношение речи к действительности или на выбор и функции отдельных выражений в составе речи. Их основными признаками являются, во-первых, отсутствие денотата: значения непредметны, поэтому изучение этих слов возможно через употребление; во-вторых, установление отношений между двумя или более субъектами дискурса. В процессе акта вербальной коммуникации определенного временного отрезка частицы и модальные слова, союзы и наречия, наряду с другими словами, обеспечивают связность текста, определяя стратегию и продолжительность коммуникации. Таким образом, частицы и модальные слова, обычно распределяющиеся по спискам различных частей речи, образуют ядро дискурсивной лексики, которое не составляет естественный класс единиц, не имеет четких границ [Дискурсивные слова... 1998: 8]. Особенностью дискурсивных слов является также их десемантизированность в дискурсивных употреблениях. Но наличие семантики в недискурсивных употреблениях создает проблему определения синтаксического статуса этих слов. При этом между дискурсивным и недискурсивным употреблением одного и того же слова часто не существует непосредственной семантической связи: в результате исследователи не соотносят друг с другом различные функции слова в дискурсе, описывая дискурсивные употребления отдельно от прочих употреблений слова [см. указ. словари]. 
По мнению И. М. Кобозевой и Л. М. Захарова термин «дискурсивные слова», не ставший пока общепринятым, очень удобен, так как ставит во главу угла семантическую специфику слова - его участие в соотнесении «вещественного» содержания высказывания с коммуникативной ситуацией, отодвигая на второй план его формальные характеристики [Кобозева, Захаров 2004: 292-297]. Акцентируя функционально-семантический аспект обозначаемого типа языковых единиц, термин «дискурсивные слова» позволяет обойти проблему их принадлежности к одной из традиционных «частей речи», дает необходимую свободу для выявления их формальных свойств, с учетом которых только и может быть произведено их адекватное разбиение на лексико-грамматические категории (классы, типы) [Кобозева, Захаров 2004: 293]. Условием отнесения служебных слов к дискурсивным является их способность устанавливать отношения между составляющими элементами структуры дискурса, понимаемого как коммуникативная ситуация, включающая сознание коммуникантов и создающийся в процессе общения текст, описывающий в высказывании фрагмент действительности и отражающий при этом процесс взаимодействия говорящего и слушающего для выражения разного рода оценок, мнений участников коммуникации и т. д. Теоретическим посылом для выделения в языке дискурсивных слов является отрицание наличия у слова значений, основанное на общих закономерностях варьирования семантики дискурсивных слов, обусловленных воздействием на них ряда стандартных контекстных условий. По мнению авторов анализируемых словарей, существуют общие закономерности варьирования семантики дискурсивных слов, обусловленные воздействием на них некоторых стандартных контекстных условий. Характеристика значения дискурсивных слов образуется из инвариантного общего компонента смысла и из обусловленного контекстом компонента. Абстрактный инвариантный компонент предопределяет возможности наполнения семантическим содержанием грамматической формы слова. Для семантики дискурсивных слов характерна субъективность, в результате которой наблюдается различная трактовка значений одних и тех же частиц и модальных слов в толковых словарях. Проведение границы между значением дискурсивного слова и контекстом является сложной процедурой: многие частицы, полностью сливаясь с контекстом, дублируют семантику его отдельных фрагментов.

Выделяются следующие морфологические и синтаксические признаки, присущие дискурсивным словам: во-первых, это их неизменяемость; во-вторых, неспособность быть ядром синтаксической группы (в отличие от существительных, глаголов, прилагательных и наречий); в-третьих, синтаксическая функция союза или адъюнкта; в-четвертых, возможность синтаксически связываться как с именной, так и с глагольной группой (в отличие от абсолютного большинства прилагательных и наречий); в-пятых, при нейтра- 
льном порядке слов бо́льшая удаленность от ядра группы препозитивных «дискурсивных» адъюнктов по сравнению с «недискурсивными» [Кобозева, Захаров 2004: 292-297].

Указанные словари используют элементарный метаязык - язык второго уровня, употребляемый авторами для разрешения проблем и противоречий семантизации дискурсивных слов, которые образуют язык первого уровня. Применяемый в этих словарях метаязык представляет собой особый семантический язык, содержащий постоянные комплексы элементарных значений, факультативные компоненты и переменные (например, графические знаки $\mathbf{X}, \mathbf{Y}, \mathbf{Z}$ и др.) единицы. Постоянные комплексы состоят из совокупности элементарных и промежуточных значений, которые позволяют отразить те или иные аспекты смысла слов. Факультативные компоненты - это возможные, но не обязательные элементы смысла. Переменные единицы указывают на семантические актанты заглавной единицы.

Синтаксис метаязыка представлен структурой, в которой предикаты рассматриваются как одноместные имена свойств с аргументом $\mathbf{S}$, приписанным ему свойством P. Эта структура дополнена модальной рамкой $\mathbf{M}$, которая дает возможность интерпретировать семантические различия дискурсивных слов, позволяющие установить смысловую структуру единиц с прагматическим компонентом. Применяемый в этом словаре метаязык призван вскрыть самые тонкие семантические различия с помощью исчисления высказываний, опирающихся на логически истинные преобразования, то есть применяемый в этих словарях синтаксис метаязыка позволяет выявить глубинные структуры высказываний, в которых использованы дискурсивные слова [см. указ. словари].

Авторами словаря Дискурсивные слова русского языка: Опыт контекстно-семантического описания был предложен иной концептуальный аппарат, позволяющий выявить те области функционирования лексической системы в целом, которые не охватывались традиционными методами описания семантики, аппарат, который основывается на мнении, что принятое в лингвистической семантике понятие значения, вряд ли может послужить основой для моделирования окружающей реальности [Дискурсивные слова... 1998: 10]. В теоретическую основу этого концептуального аппарата было положено понятие варьирования, позволяющее рассматривать значение слова как равнодействующую разных типов вариаций его плана содержания. Нельзя не согласиться с мнением исследователей, что варьирование плана содержания происходит не только по «оси значений», но и по параметру усиления-ослабления значимости тех или иных компонентов его семантики. Предлагаемый в анализируемых словарях контекстно-семантический подход основывается на идее варьирования плана содержания под влиянием факторов контекста. С целью описания дискурсивных слов вы- 
деляются три типа их варьирования: различаются внутренние компоненты семантики слова (различные компоненты плана содержания слова могут быть более или менее значимы), моделируемые в словаре с помощью понятия «грани» и внешние компоненты, моделируемые с помощью понятия «деформации»; третий тип варьирования связан с понятием сферы действия дискурсивного слова, определяемый общими закономерностями интонационного оформления, порядка слов и актуального членения. Каждая грань соответствует преобладанию одного из компонентов плана содержания или равенству компонентов по значимости, то есть представляет собой внутреннее варьирование плана содержания дискурсивного слова. Понятие внутреннего варьирования дискурсивного слова связано с предположением о внутренней гибкости и изменчивости слова, которая основывается на том, что компоненты плана содержания могут менять свою относительную значимость. Закономерности внутреннего варьирования описывают, «каким образом внутреннее ,устройство” слова соотносится с разными способами его контекстуализации, причем эти способы контекстуализации определяются общими принципами построения высказывания», а варьирование, связанное со сферой действия, «задает некоторую классификацию дискурсивных слов на основании ряда признаков, таких, как сфера действия дискурсивных слов, расположение в предложении, тип интонации и тип акцента, тема-рематическая структура и других» [Дискурсивные слова... 1998: 12]. Авторы словаря отмечают, что возникающие деформации слова как результат воздействия контекстных и ситуационных факторов непредсказуемы, в то же время деформации нельзя считать произвольными, поскольку возможности «деформирования» слова извне (то есть его внешнего варьирования) ограничены возможностями его внутреннего варьирования [там же, с. 12-13].

Введенные в научный лексикон понятия гаранта и установочной базы имеют принципиально важное значение для описания и классификации дискурсивных слов. Синонимом понятия гарант является понятие субъект коммуникации, коммуникант (языковая личность). Понятие гарант связано, во-первых, с понятием выделения, во-вторых - с соотношением истинности и адекватности, в-третьих - с неопределенностью гаранта, которая составляет специфику плана содержания некоторых дискурсивных слов [Дискурсивные слова... 1998: 29]. Установочной базой является фрагмент высказывания, который вводится в текст и детерминирован в связи с некоторым объективным внешним или субъективным положением вещей или заданностью объективной действительности. Одна из функций дискурсивных слов заключается именно в таком соположении двух высказываний, когда фрагмент высказывания или высказывание, вводимые дискурсивными словами, выступают в роли установочной базы к некоторому положению действительности, описанному в контексте или заданному ситуативно. 
Выделение для дискурсивных слов понятий гаранта и установочной базы позволяет показать, что дискурсивные слова, обладая своей семантикой, «в то же время определенным образом соотносятся с общими принципами построения дискурса» [Дискурсивные слова... 1998: 31].

Авторами словаря Дискурсивных слов русского языка выделено четыре класса слов:

1) слова, сопоставляющие элемент и множество (класс) элементов;

2) слова, вводящие в рассмотрение несколько реализаций одного положения вещей;

3) слова, связанные с понятием установочной базы;

4) слова, связанные с понятием гаранта.

Первые два класса выделяются на основании семантических признаков (наличие элемента и/или класса элементов; наличие двух реализаций одного положения вещей), тогда как третий и четвертый классы соответствуют двум способам построения дискурсивной последовательности. Категория «положение вещей» понимается в трех основных смыслах. Во-первых, положение вещей - это некоторая часть действительности, объективного мира, которая описывается пропозицией (положением вещей 1). Во-вторых, под положением вещей имеется в виду абстрактное, обобщенное представление о действительности - результат типизации в языке положений вещей 2. Положение вещей 2 пренебрегает различиями между сходными положениями вещей 1, фиксируя то общее, что у них есть. Положение вещей 3 связано как с положением вещей 1, так и с положением вещей 2. Словарная статья включает зоны, которые расположены в следующем порядке: заголовок, эпиграф, мир слова, истоки, сценарий, грани, деформации (особые употребления). Зоны «сценарий», «грани», «деформации» составляют ядро словарной статьи данного словаря. К вспомогательным зонам отнесены «заголовок статьи», «мир слова», «истоки». Факультативные зоны «эпиграф» и «особые употребления» призваны выявить и подчеркнуть наиболее яркие и интересные особенности контекстного употребления слова [Дискурсивные слова... 1998: 31].

Описания слов в словарных статьях анализируемого словаря принципиально отличаются как от традиционных словарных описаний, так и от анализа дискурсивных слов в лингвистической литературе. Предлагаемые авторами словаря содержание и структура словарной статьи и кодифицируемые единицы дают представление о возможности иного, в отличие от традиционного, подхода к слову, по-иному представляет типы варьирования употребительности дискурсивного слова, характеризуются абстрактным описанием плана содержания слова. Для словарных статей характерно подробное описание коммуникативных составляющих, которые могут быть сферами действия дискурсивных слов, а также указание на соотнесенность 
значения слова с актуализационными характеристиками. Проанализированные словари предназначены, в первую очередь, для лингвистов, решающих задачи теоретического порядка, а именно для исследований в области дискурсивных слов, их места в языке, их функций и т. д. Для прикладных нужд словари могут быть полезны при лингвистическом анализе литературного текста филологами, в преподавании курса современного русского языка на филологических факультетах вузов [см. указ. словари]. Словарь, предназначенный для лингвистов, изучающих дискурсивные слова с научной точки зрения, вряд ли может быть использован такими группами пользователей, как учащиеся средних школ и студенты вузов, изучающих русский язык как неродной и русский язык как иностранный.

Недостатком указанных словарей является то, что в основном анализу подвергнуты примеры из художественной литературы, а не из интеракции - реальной устной речи, отображающей коммнукативный акт адресанта и адресата.

\section{Библиография}

Баранов А. Н., Плунгян В. А., Рахилина Е. В. [1993], Путеводитель по дискурсивным словам русского языка, Москва.

Киселева К. и Пайар Д. (ред.) [1998], Дискурсивные слова русского языка: Опыт контекстно-семантического описания, Метатекст, Москва.

Кобозева И. М., Захаров Л. М. [2004], Для чего нужен звучащий словарь дискурсивных слов русского языка?, Доклады международной конференции Диалог 2004, Москва, с. 292297.

Плунгян В. [2013], Дискурсивные слова, http://postnauka.ru/faq/8572

Плунгян В. А., Рахилина Е. В. [1994], О некоторых направлениях современной франиузской лингвистики, «Вопросы языкознания», № 5, с. 107-125. 